\title{
Design in Times of Pandemics: Accessible literature to people with visual impairment
}

\author{
Mônica Moura \\ UNESP/Bauru \\ São Paulo, Brazil \\ monica.moura@unesp.br
}

\author{
Cristina Portugal \\ $\mathrm{PQ} / \mathrm{Cnpq}$ \\ Rio de Janeiro, Brazil \\ cristina.portugal@pq.cnpq.br
}

\author{
Márcio Guimarães \\ UFMA \\ Maranhão, Brazil \\ marcio.guimaraes@ufma.br
}

\begin{abstract}
This paper shows a pilot project named "Lembrei de você" (I remember you) that has as its goal to create a network of sharing messages made by people that, by means of their voice and their message, wake up feelings of empathy, reception, comfort and hope to other people in a state of loneliness during the SARS - Covid-19 pandemics. By means of audios made available, the project aims to increase the aesthetic-sensitive repertoire of information that may stimulate mental images and memories, aiming to strength the self-esteem, promoting autonomy and, in consequence, the social inclusion of people with visual impairment and elderly, as well as to include other people.
\end{abstract}

Inclusive design. Accessibility. Visual impairment. Elderly. Pandemic.

\section{INTRODUCTION}

This paper is part of a research project sponsored by $\mathrm{CNPq}$ - National Council for Scientific and Technological Development from Brazil, that brings together the contemporary relations of Design resuming their guiding principles expressed from actions related with social responsibility and citizenship; the effective contribution by means of the social problems existing in Brazil, which are especially addressed in the sphere of inclusive and accessible design, with the priority of improving the quality of life and the well-being of individuals.

The study in question has as priority audience the group of blind elderly people with low vision due to the vulnerability and fragility inherent to those elders, especially in face of the loneliness, an issue that they pointed out as being one of the most serious problems to be faced.

Given the situation of social isolation imposed by SARS - Covid-19 pandemics, this feeling of loneliness is aggravated. This fact leads us to the need of developing practices related with the universe of inclusive and accessible design, guided by a theoretical body that enables an effective system for communication, interaction and integration in a network supportive to elderly people with visual impairments, providing an effective relationship between university and society based on the scientific knowledge developed.

The objective of this work is to present a pilot project whose proposal was to create a network of people who, through their voice and message, arouse feelings of empathy, welcome, comfort and hope to other people in a state of solitude during the pandemics. In order to meet this goal, we created a network of volunteer mediators/organisers, readers and listeners.

Participants of the project are volunteers who work in the organization and mediation group, in the group of readers who, together, serve a network of listeners (individual people, local agents who work with other small groups or communities and institutions of elderly, youth and children members, with or without disabilities). This network of listeners was formed with recommendations from the project's own volunteers and will be expanded by means of an action of public relations.

This is an emergency action to fill the need of people who feel lonely and isolated, but the project foresees several other more complex actions in the short, medium and long term.

Associating language, orality, literature and other artistic or popular expressions via oral manifestation and bringing together a group of volunteers to be readers forming a network with other people, individually, collectively or institutionally, with elderly people, with or without visual impairment, we laid the foundation for our inclusive and accessible design project.

However, the application of the pilot project pointed us to two extremes. On the one hand, the effectiveness with positive responses of listeners served; on the other hand, the indication of an 
urgent need for a broader and deeper systematization in order to achieve greater effectiveness and better dynamics, expanding the accessibility.

From the need of involving not only the pandemic period, but also the post-pandemic period, we were led to an unfolding and expansion of the pilot project or to a digital management, communications and interaction platform.

The creation and implementation of a digital platform aims to facilitate the management, communication and collection of audio messages that enables the interaction of blind and visually impaired elderly people, with and without visual impairment, integrating a network of listeners and readers by means of interdisciplinary and participatory action, mediated by an inclusive and accessible design, in order to promote empathy, expanding the repertoire of information, aesthetic, sensitive and stimulating mental images and memories aiming to strengthen the self-esteem and to promote motivation for the construction of autonomy and, consequently, inclusion in society.

In order to meet this objective, we adopted the qualitative method with bibliographic, documentary and field research approaches, associated with collaborative and participatory processes serving groups and involving evaluation, validation and improvements in the developed processes.

By adapting to the countless contemporary cultural, social and technological innovations and dialoguing with different fields of research, design is resignified and follows paths that are increasingly alternatives to the initial concepts which associates it solely with the industrial production. This project addresses a reflection regarding the performance of human-centered design and some of its consequences, such as co-creation and other perspectives of performance, supported by an argument built from the discourse of contemporary design scholars. In it, we reflect about the role of design in social contexts, especially in an activity in which the subjects participating on it become coresponsible for the results obtained.

When adapting to the countless contemporary cultural, social and technological innovations and dialoguing with different fields of research, design is re-signified and follows paths that are increasingly alternative to the initial concepts that associated it solely with industrial production. This project addresses a reflection on the performance of human-centred design and some of its consequences, such as co-creation and other perspectives of action, supported by an argument constructed from the discourse of contemporary design scholars. In it, we reflect on the role of design in social contexts, especially in an activity in which the subjects participating in the research become co-responsible for the results obtained.

Visual impairment is characterized by a decrease, loss or absence of visual acuity or visual field. These two ophthalmic scales concern the ability or inability to see at a distance (visual acuity) and the amplitude of the area reached by the vision (visual field).

The most recent survey on disability in Brazil was carried out by the Brazilian Institute of Geography and Statistics - IBGE in 2010, being reiterated and released by the Brazilian Council of Ophthalmology - $\mathrm{CBO}$, and points out that the number of citizens diagnosed with visual impairment surpassed the 6 mark, 5 million people, of which 6 million are people with low vision and 500,000 are blind people.

According to Ottaiano et al. (2019), data based on the world population in 2016 show the increase in the number of blind people in the elderly population (over 60 years) as a result of longer life. Over $82 \%$ of all blind people in the world are over 50 years old, despite the fact that this group represents $19 \%$ of the world population. According to the IBGE (2019), the elderly population should double in Brazil by the year 2042, in comparison with the numbers of 2017, when the country had 28 million elderly people, or $13.5 \%$ of the total population. In ten years, it will reach 38.5 million $(17.4 \%$ of the total inhabitants).

In view of this reality and reflecting on the basic principles of design, we are concerned about the search for solutions and contributions to improve the quality of life and well-being of people with visual impairments. And, in recent years, we have dedicated ourselves to the study and research related to the ways in which design contributes to people with visual impairments, which is often referred to as social design.

Thus, we believe that the great challenge of contemporary design is to be developed in a sphere that understands the complexity and diversity of people who live the reality of our time and, therefore, in agreement with the arguments of the authors that we will present in this reflection, we consider that the search for real improvement in the quality of life is configured as one of the aspects encompassed by contemporary design, looking for solutions to current social problems, in which one of the most prominent and also complex aspects is inclusion, especially in these times of social isolation in the face of the Covid-19 pandemic. 


\section{METHODOLOGY}

To meet the objectives, we adopted the qualitative method with bibliographic, documentary and field research approaches, associated with collaborative and participatory processes of the group served and involving evaluation, validation and improvements in the developed processes.

We will take as a basis the Social Model of Design Practice developed by Margolin (2004), which can be applied with the collaboration of different professionals, be they from health, education, or public administration. Margolin (2004) points out that the participation of processes and projects involving teams of human services and designers is still open to be explored and that there are two main reasons for the fact that there is no greater support for social design: the absence of a program of education and training in design schools and the absence of research demonstrating how a designer can contribute for the human well-being (2004, pp.45-46).

The proposed Margolin model involves 6 stages, namely: 1. Commitment; 2. Evaluation; 3. Planning; 4. Implementation; 5. Estimate; 6. Finalization. Our details involve the following sub-stages: 1.1 Listening to learn about the problem and reality of people served (target audience); 1.2 Involvement in order to search for a joint solution (co-creation, participation, diffuse and specialist design); 2.1 Examine and promote interaction; 2.2 Analyse and understand the problem; 2.3 Generate a list of needs; 3.1 Prioritize urgencies; 3.2 Promote brainstorming in search of the solution; 3.3 Develop a list of goals and objectives for each one involved in the process; 4.1 Intervene according to goals and goals defined in the planning; 5.1 Evaluate by means of interviews with the public served and validate the process and 6.1 Evaluate the dynamics and the general process. Produce and publish scientific papers, chapters and books about results obtained.

\section{PILOT PROJECT: “LEMBREI DE VOCÊ”}

The Covid-19 pandemic is undoubtedly a huge challenge for everyone in the world. However, the impact occurs in different ways and degrees, impacting more strongly those people whose living conditions were already in situations of exclusion. In the development of previous researches and in the application of projects with groups and institutions of elderly and blind ones, it was identified that the major and main problem affecting these elderly people, blind or with low vision is loneliness.
In face of the constitution of a theoretical body and of the development of practices related to the universe of inclusive and accessible design in contemporary times, we began to question ourselves what our role was and how we could contribute to people in general, but with accessibility for those with visual impairments, in the situation of social isolation imposed by the SARS - Covid-19 pandemic. After all, what were we designers doing for the public that we worked with to lessen this feeling of loneliness during quarantine?

And, thus, the project entitled I Remembered You was born. The purpose of this project is to be inclusive, that is, aimed at all people who are or feel lonely or in a state of loneliness in this pandemic, of any age and, also, accessible to people, elderly or not, visually impaired, regardless of age, city or location, but as long as they have access to a mobile phone with WhatsApp.

The main objective is to create a network of people who, by means of their voice and message, arise feelings of empathy, welcome, comfort and hope to others in a state of solitude during the pandemic. To meet this objective, we have created a network made up of volunteer mediators / organizers, readers / tellers and listeners.

The participants in the Remembered You project are volunteers who work in the organization and mediation group, in the group of readers / tellers who, together, serve a network of listeners (individual people, people, local agents who work with other small groups or communities and institutions for the elderly, young people and children with or without disabilities). This network of listeners was created with recommendations from the project's own volunteers and will be expanded by means of an action of public relations.

This is an emergency action to fill the needs of people who feel lonely and isolated, but the project foresees several other more complex actions in the short, medium and long terms.

Associating language, orality, literature and other artistic or popular expressions via oral manifestation and bringing together a group of volunteers to be tellers, forming a network with other people, individually, collectively or institutionally, elderly people with or without visual impairment, we lay the foundations for our inclusive and accessible design project.

However, the application of the pilot project pointed us to two extremes. On the one hand, the effectiveness with positive responses of the listeners served, on the other hand, indicated the urgent need by a broader and deeper 
systematization to achieve greater effectiveness and better dynamics, expanding the accessibility.

\section{Target Group}

Elderly, adults and children in isolation during the pandemic, accessible to people with visual impairments (blind and low vision).

\subsection{Working Process of "Lembrei de Você"}

The process happens as follows:
Volunteers record audios with verses, poetry, short stories, stories, reports from individual or collective memory, songs of their own or not and send the audios to a WhatsApp group where they will be documented and stored on a platform. Subsequently, they will be checked to see if there is noise, an inaudible voice, etc. and, after this process, they will be sent to registered groups of listeners.

The project has participants with different roles for: volunteers, listeners and institutions.

\section{I remembered You \\ Project Organization Visual Map}

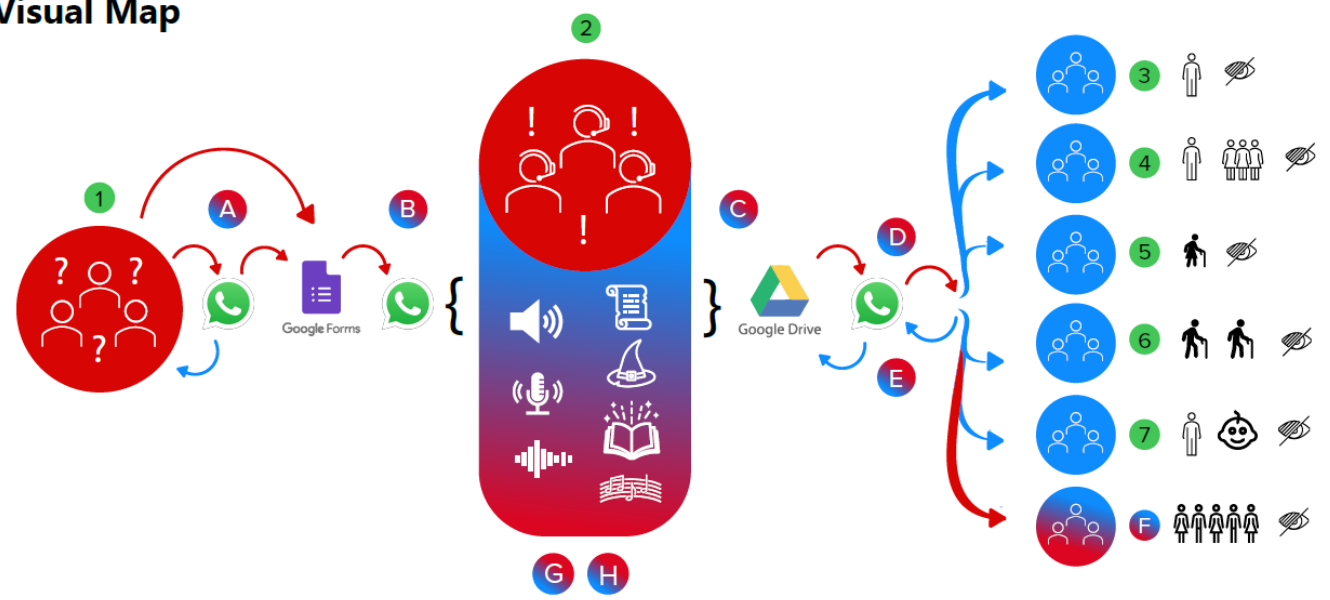

\section{I remembered You Visual Map \\ Colors:

Organization
Volunteers
Listeners
Whatsapp Group

Symbols:

\begin{tabular}{|c|c|}
\hline 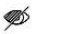 & Incidence of the Blind/Low Vision \\
\hline 饵 & Individuals \\
\hline 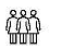 & Groups \\
\hline क & Small /medium-sized Institutions \\
\hline 为为 & Large Institutions \\
\hline & Children's Institutions \\
\hline 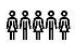 & New Institutions \\
\hline
\end{tabular}
Organization:
A A service to volunteers
Responsible: Valéria
B Inserting contacts to the Group
Responsible: Maria Alice
C Audio selection and documentation
Responsible: lana, Márcio, Mônica, Cristina, José and Tetê.
D Sending Audios
Responsible: Mônica and Cristina
E Colection of testimonials/feedbacks
Responsible: Valéria
F Contact with Institutions (Expansion)
Responsible: Márcia
G Textual revision
Responsible: Márcia
(H) Coordination and Project (Registration and Notices) Responsible: Cristina, Márcio e Mônica
Whatsapp Groups:

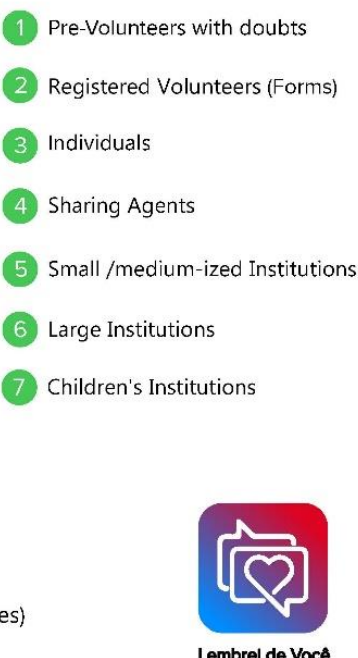
1) Pre-Volunteers with doubts
2 Registered Volunteers (Forms)
(3) Individual
4) Sharing Agents
(6) Large Institutions
7. Children's Institutions

Figure 1: Reading guide of the Visual Map of Project. "Lembrei de Você". Source: Elaborated by Author (2020). 


\subsubsection{For volunteers}

- The volunteer will receive a link for each record. Accessing the link, it will fill with the personal data and must agree with the Term of Assignment to Use Audiovisual Resources and, them, click in SEND.

- After validating the record of each volunteer, this one will be added in a group for sending messages using WhatsApp.

- In this new group, volunteers must send the audios that will be stored on the Cloud, catalogued, verified and later, directed for the listeners.

- The volunteer will receive a PDF file with a suggestion about how the recording must be made, the presentation, Project name, type of message, text, poem, tale, and... the farewell, in order to standardize the approach of audio for this project.

- Audios must have a minimum time of two minutes and, at most, 15 minutes. Content may be constituted by histories, tales, stories, music, poems, legends, memories and personal reports of memory (from their Family, their friends or fictional).

- The proposal is to have one audio per week for each volunteer, but volunteers are free to send as much as they want.

- If some external interference happens, such as noise covering the voice of volunteers, we will indicate (privately), the need of redoing the audio after verification.

- The initial group of volunteers will remain active to answer questions and exchange experiences. If there is feedback from any listener or group of listeners, we will also post it in the volunteers group.

\subsubsection{For listeners}

- Listeners will receive an invitation to receive audios. They will have access to one audio per week.

\subsubsection{For institutions}

- The volunteer who assumed the role of public relations (PR) in the project "I Remembered You" will have to collect the indications of institutions from the other volunteers and, also, make a survey to organize a database of institutions to be served.

- The contact with institutions will occur by email from the project (projetolembreidevoce@gmail.com) or
WhatsApp to collect the contact data in order to send the form to be filled out.

- If the institution agrees to participate, the person responsible for the institution receives a link to access a Google form, which must be filled and, after this stage, the institution's mobile number will be added to start receiving a message once a week during three months. After this period, we will carry out an evaluation of the project. We will adjust according to the needs of each institution. At first we will be able to increase the number of times of sending messages, for example, two days, then three, until reaching a daily message.

- The RP monitors the answers of institutions' messages and informs the organizing group in order to send the messages and, subsequently, if institutions ask for message themes or types (poetry, short story, story, music, legend, personal or collective memory report)).

\subsubsection{Team of Project "Lembrei de você"}

The multidisciplinary team was made up of professionals from different areas, designers, illustrators, pedagogues, musicians, programmers and professionals of Letters, led by Researchers Monica Moura, Márcio Guimarães and Cristina Portugal, all of them designers and doctors in Design. It also has ten people in the organization / mediation; 69 volunteers so far and 300 audios, among tales, poetry, music, etc. recorded and stored for distribution. The audios will be made available weekly to listeners in individual groups, agents of small groups and institutions, the latter being divided into institutions for adults and for children.

The innovation involved in the project will take place based on the expected results and occurs especially because there is little bibliographic production with cases and Brazilian reality for people with visual impairments.

And, finally, it is expected to create a digital platform, from the studies, analyses, evaluations and surveys carried out, the planning and execution of the beta version of the digital platform for managing communication, collection and distribution of content for the visually impaired ones, including and also targeting visionary people, since accessible and inclusive projects must meet and provide comfort to everyone. Also, it is expected that the results obtained will contribute to the creation of autonomy and, consequently, the well-being and improvement of the quality of life of the individuals participating in the research. 


\section{CONCLUSION}

This project brings new models, new methods and new approaches for the development of virtual spaces by means of digital platforms to reduce the state of loneliness in which these people are, that can provide meaningful information and create pleasant experiences.

After the implementation of this pilot project and the analysis of results, we realized the need to create and implement a digital platform for management, communication and collection of audio messages that enables the interaction of elderly blind people with low vision, with and without visual impairment, integrating a network of listeners and readers through interdisciplinary and participatory action, mediated by inclusive and accessible design, in order to promote empathy, to expand the repertoire of information, aesthetic, sensitive and to stimulate mental images, memories and memories aiming at strengthening self-esteem and promoting motivation for the construction of autonomy and, consequently, inclusion in society.

In social isolation, the feeling of loneliness worsens and adds to the insecurity and awareness of our fragility and finitude, as we are all at the mercy of a moment to be affected by a serious illness that can lead to death or to treatments and invasive procedures.

Also, if contact with other people during the pandemic is not feasible, whether inside the homes or in the public space, a way to reduce the feeling of loneliness is to take the voice of another ordinary person (not famous people) at regular intervals for those who are in a state of solitude. And what better way to take someone else's voice than literature in its several genres (narrative, lyrical, dramatic) and, also, songs, stories of life stories, memories, and souvenirs?

In this sense, it is necessary to search for solutions in order to create information and communication management systems that are currently inserted in an environment of permanent challenge and that requires updating and developing new forms of presentation in addition to traditional ones, in order to make them understandable and usable by people with visual impairments.

\section{ACKNOWLEDGMENT}

CNPq - National Council for Scientific and Technological Development from Brazil, Mônica Moura, "Bolsista de Produtividade de Pesquisa (PQ)" - Proc. N N. 314690/2020-4

Cistina Portugal, "Bolsista de Produtividade de Pesquisa (PQ)" - Proc. №. 308786/2018-1.

\section{REFERENCES}

Guimarães, M. J. S. (2020). Design inclusivo na contemporaneidade: diretrizes ao desenvolvimento de materiais didáticos acessíveis para crianças cegas e com baixa visão. Bauru, 2020. Tese (Doutorado) - Faculdade de Arquitetura, Artes e Comunicação, Universidade Estadual Paulista (Unesp).

INSTITUTO BENJAMIN CONSTANT - IBC. (2008). O processo de adaptação de livros didáticos e Instituto Benjamin Constant, Rio de Janeiro: IBC.

INSTITUTO BRASILEIRO DE GEOGRAFIA E ESTATÍSTICA - IBGE. (2010) Dados censitários MA.

RTIViewer:

http://www.ibge.gov.br/estadosat/temas.php?sigla= ma\&tema=censodemog2010. (retrieved 01 March 2021).

Manzini, E. (2015). Design When Everybody Designs: an introduction to Design for Social Innovation. London: MIT Press.

Margolin, V., Margolin, S. (2004). Um Modelo Social de Design: questões de prática e pesquisa. Revista Design em Foco, Salvador: EDUNEB, v.1, n. 1, jul./dez., p. 43-48.

Moura, M., Portugal, C., Perez, I. U.; Torres, M. A.; Guimarães, M. Design Contemporâneo e Inovação social aplicados no desenvolvimento de produtos gráficos educativos para pessoas com deficiência visual. $9^{\circ}$ CONGRESSO INTERNACIONAL DE DESIGN DA INFORMAÇÃO, 2019, Belo Horizonte. Blucher Design Proceedings, 2019. p.779.

Ottaiano, J. A. A., Ávila, M. P. Umbelino, C. C., Taleb, A. C. (2019). As condições de saúde ocular no Brasil 2019. São Paulo: Conselho Brasileiro de Oftalmologia - CBO.

Papanek, V. (1971). Design for the real world. Londres: Thames \& Hudson.

Portugal, C., Brunnet, N. (2016). Design and the creation of an Interactive Academic Space Electronic Visualisation and the Arts (EVA 2016), London, UK, 12-14 July 2016, 170-177. BCS, London.

Sacks, O., Slegel, R. M. (2006). Seeing is believing as brain reveals its adaptability. Carta ao editor. Nature 441 (7097), p. 1048. 